\title{
Antioxidant activity of Rosa multiflora Thunb. flower extract and suppressive activity on proinflammatory mediator production in lipopolysaccharide- stimulated RAW 264.7 macrophages
}

\author{
Chung Shil Kwak ${ }^{1 *}$, Hye In $\mathrm{Choi}^{2}$, Jiwon Yang ${ }^{1}$
}

${ }^{1}$ Institute on Aging, Seoul National University, Daehak-ro, Jongno-gu, Seoul 03080, South Korea; ${ }^{2}$ Institute of Dermatological Science, Daehak-ro, Jongno-gu, Seoul 03080, South Korea

*Corresponding author: Chung Shil Kwak, $\mathrm{PhD}$, Professor, Institute of Aging, College of Medicine, Seoul National University, \#304 Biomedical building, 103 Daehak-ro, Jongno-gu, Seoul 03080, South Korea

Submission Date: March 7, 2016, Acceptance Date: May 25, 2016, Publication Date: May 30, 2016

\begin{abstract}
Background: Oxidative stress and inflammation are associated with various age-related chronic diseases. The fruits and roots of Rosa multiflora Thunb. have been used in medicine for the treatment of edema and inflammatory diseases in Eastern Asia. Dried Rosa multiflora Thunb. flowers (RMF) are consumed as a tea in Korea, but reports on the biological activity of RMF are lacking. We evaluated the in vitro antioxidant and anti-inflammatory effects of an ethanol extract from RMF as well as various solvent fractions from the extract.
\end{abstract}

Methods: The ethanol extract (Et) of RMP was fractionated sequentially by hexane (Hx), dichloromethane (DM), ethyl acetate (EA), n-Butanol (Bt), and water (DW). Total phenolic and flavonoid contents, scavenging activities of the 2,2-diphenyl-1 picrylhydrazyl radical, 2,2'azinobis-3-ethylbenzothiazoline-6-sulfonic acid radical, and ferric-reducing antioxidant power were measured. Anti-inflammatory effects in terms of levels of nitric oxide (NO), prostaglandin (PG) E2, and production of pro-inflammatory cytokines such as interleukin (IL)-6, tumor necrosis factor (TNF)- $\alpha$ in lipopolysaccharide (LPS)-treated RAW 264.7 macrophages were measured. The expression of inducible nitric oxide synthase (iNOS) and cyclooxygenase (COX)2 were measured by the Western blot analysis.

Results: EA demonstrated the highest total phenolic and flavonoid contents and strongest antioxidant activity, followed by Bt and Et. Treatment with Et, Hx, DM, EA, Bt, and DW significantly suppressed $(\mathrm{p}<0.05) \mathrm{NO}$ production in a dose-dependent manner in LPS-treated RAW 264.7 macrophages via reduction of expression of iNOS protein. Treatment with Et, DM, and EA significantly suppressed $(\mathrm{p}<0.05)$ PGE2 production induced by LPS treatment; however, only Bt treatment significantly reduced $(\mathrm{p}<0.05)$ the expression of COX-2 protein. Treatment with EA and Bt suppressed IL-6 production significantly $(\mathrm{p}<0.05)$ in LPS-treated RAW 264.7 
macrophages. Treatment with Et, DM, EA, and Bt suppressed TNF- $\alpha$ production significantly $(\mathrm{p}<0.05)$.

Conclusion: These data suggest that the ethanol extract of Rosa multiflora Thunb. Flowers and its dichloromethane, ethyl acetate and n-Butanol fractions have potent antioxidant and/or antiinflammatory activities.

Keywords: Rosa multiflora Thunb, flowers, antioxidant activity, anti-inflammatory activity, RAW 264 7, macrophages, cytokines, iNOS, COX-2

\section{INTRODUCTION}

Overproduction of reactive oxygen species (ROS) can cause oxidative damage to membrane lipids, DNA, proteins, and lipoproteins. This kind of damage can eventually lead to chronic diseases such as cancer, diabetes mellitus, arthritis, Alzheimer's disease, or cardiovascular diseases [1]. ROS are stimulators of the inflammatory response via lipid peroxidation of cell membranes and activation of intracellular signaling pathways, including nuclear factor-kappa B (NF-kB) [2-4].

Inflammatory diseases such as rheumatoid arthritis, asthma, multiple sclerosis, inflammatory bowel disease, and psoriasis are common diseases worldwide [5]. Inflammation is the primary defense reaction from the host. It is considered to be a beneficial and necessary attempt by the organism to eliminate an aggressive agent. However, serious diseases may develop if chronic inflammation occurs [6].

Nitric oxide (NO) is a free radical generated through conversion of L-arginine to citrulline; the reaction is catalyzed by nitric oxide synthase (NOS). High levels of NO have been closely correlated with the pathophysiology of various inflammatory diseases. Therefore, suppression of excessive release of ROS and NO could protect against the development of oxidative stress and/or inflammation-related diseases [7].

Macrophages have important roles in the inflammatory response. If activated, macrophages release NO, proinflammatory cytokines including interleukin (IL)-1, IL-6, tumor necrosis factor (TNF)- $\alpha$, and lipid mediators including prostaglandin (PG) E2, which promote inflammation by stimulating cellular migration to the target site [8]. Lipopolysaccharide (LPS) activates various mammalian cell types (e.g., monocyte/macrophages, endothelial cells) and induces expression of various proinflammatory mediators [9].

Rosa multiflora is commonly known as multiflora rose, baby rose, many-flowered rose, or seven-sisters rose. Rosa multiflora is a species of rose native to eastern Asia, including Korea, China, and Japan. The fruits and roots of this plant have been used for centuries as folk medicine for the treatment of edema, arthritis, and beriberi in Eastern Asia, including Korea and China [10, 11]. A few studies on the antioxidant and anti-inflammatory activities of those plant parts have been reported $[5,10,12,13]$. In Korea, the steamed and dried flowers of Rosa multiflora Thunb. are consumed as a tea, but reports on their biological functions are lacking. 
We aimed to evaluate the antioxidant and anti-inflammatory activities of the ethanol extract and its several fractions of Rosa multiflora Thunb. flowers (RMF) using RAW 264.7 macrophages.

\section{METHODS}

\section{Sample preparation, extraction and fractionation}

RMF were picked from trees in the Gangwon Province (a mountainous part of eastern Korea) in May 2015. A voucher specimen (2007-0212) has been deposited at Korea University Herbarium. Harvested RMF were dried at $45^{\circ} \mathrm{C}$ for $35 \mathrm{hrs}$, shade-dried for 2-3 days in a farm, and freezedried in our laboratory (Samwon, Seongnam, Korea) for $24 \mathrm{hrs}$.

To obtain an ethanol extract (Et) of RMF, $50 \mathrm{~g}$ of powdered RMF was extracted in $95 \%$ ethanol (Ducksan, Ansan, Korea) ten-times (v/v) with stirring for 24 hrs. The supernatant was removed and passed through Whatman ${ }^{\mathrm{TM}}$ filter paper (No.2; Fisher Scientific, Pittsburgh, PA, USA). The residue was extracted once more with ethanol and filtered. The two filtrates were combined and evaporated using a rotary vacuum evaporator (Eyela, Tokyo, Japan) at $35^{\circ} \mathrm{C}$ to remove the ethanol. For the sequential fractionation, the concentrated Et of RMF was dissolved in distilled water (DW) and then fractionated sequentially with hexane (Hx), dichloromethane (DM), ethylacetate (EA), and n-butanol (Bt), which thereby resulted in an aqueous layer (DW). All fractions were concentrated, freeze-dried, dissolved in dimethyl sulfoxide (DMSO) or phosphate buffered saline (PBS) to $50 \mathrm{mg} / \mathrm{mL}$, and stored at $-20^{\circ} \mathrm{C}$.

\section{Determination of total phenolic and flavonoid content}

The total phenolic concentration in the ethanol extract of RMF and its fractions was determined according to the method described by Singleton et al. [14]. $100 \mu \mathrm{L}$ of the sample was briefly mixed with $1 \mathrm{~mL}$ of $0.2 \mathrm{~N}$ Folin-Ciocalteau reagent and $200 \mu \mathrm{L}$ of $20 \%$ sodium carbonate, and left in the dark for $1 \mathrm{hr}$. Absorbance was read at $760 \mathrm{~nm}$ by a spectrophotometer using tannic acid as a standard. Total phenolic content was represented in unit of mg tannic acid equivalent (TA eq.)/g.

Total flavonoid content was determined according to the modified AOAC method [15]. 100 $\mu \mathrm{L}$ of the sample was briefly mixed with $900 \mu \mathrm{L}$ of $90 \%$ diethylene glycol and $20 \mu \mathrm{L}$ of $1 \mathrm{~N}$ $\mathrm{NaOH}$, and incubated in a $37^{\circ} \mathrm{C}$ water-bath for $1 \mathrm{hr}$. Absorbance was read at $420 \mathrm{~nm}$ by a spectrophotometer using rutin as a standard. Total flavonoid content was represented in unit of $\mathrm{mg}$ rutin equivalent (RT eq.)/g.

\section{Measurement of 2,2-diphenyl-1 picrylhydrazyl (DPPH) radical-scavenging activity}

DPPH radical-scavenging activity was determined as described previously [16]. Various concentrations of each sample were mixed with $200 \mu \mathrm{m}$ DPPH solution in ethanol, incubated at $37^{\circ} \mathrm{C}$ for $30 \mathrm{~min}$, and the absorbance read at $517 \mathrm{~nm}$ by a spectrophotometer. Reduction in absorbance was proportional to the ability of the sample to eliminate DPPH radicals. Ascorbic acid was used as a positive control. DPPH radical-scavenging effect was calculated using the following equation: 
DPPH radical-scavenging activity $(\%)=\left[\left(\mathrm{A}_{\text {control }}-\mathrm{A}_{\text {sample }}\right) / \mathrm{A}_{\text {control }}\right] \times 100$, where " $\mathrm{A}$ " denotes absorbance. The $\mathrm{IC}_{50}$ value (i.e., sample concentration needed to reduce $50 \%$ of DPPH radicals) was calculated.

Measurement of 2,2'-azinobis-3-ethylbenzothiazoline-6-sulfonic acid (ABTS) radicalscavenging activity

According to the method used by Re et al. [17], ABTS and potassium persulfate were dissolved in distilled water and mixed to final concentrations of $7 \mathrm{mM}$ and $2.46 \mathrm{mM}$, respectively. After staying in the dark for $18 \mathrm{hrs}$, the mixture was diluted with ethanol to give an absorbance of $0.70 \pm 0.02$ at $734 \mathrm{~nm}$. After mixing $1.0 \mathrm{~mL}$ of diluted ABTS solution with $50 \mu \mathrm{L}$ of extract or ascorbic acid (standard) in ethanol and allowing the mixture to stay in the dark for $30 \mathrm{~min}$; the absorbance was read using a spectrophotometer. The ABTS radical-scavenging activity of the sample was expressed as $\mu \mathrm{g}$ ascorbic acid equivalent (AA eq.) $/ \mathrm{mL}$.

\section{Measurement of ferric reducing antioxidant power (FRAP)}

The method described by Yildrim et al. [18] was used for the determination of FRAP. A mixture of various concentrations of the sample in $0.2 \mathrm{M}$ phosphate buffer ( $\mathrm{pH} 6.6$ ) and $1 \%$ potassium ferricyanide was incubated in a water-bath for $30 \mathrm{~min}$ at $50^{\circ} \mathrm{C}$, followed by the addition of $10 \%$ trichloroacetic acid. After the centrifugation of the solution at $1000 \times \mathrm{g}$ for $10 \mathrm{~min}$, the supernatant was taken, mixed with $0.1 \% \mathrm{FeCl}_{3}$, and the absorbance read at $700 \mathrm{~nm}$ by a spectrophotometer. Ascorbic acid was used as a positive control. The result was expressed as $\mu \mathrm{g}$ AA eq./mL.

\section{Cell culture and cell viability}

RAW 264.7 murine macrophages were purchased from a Korean cell bank (Seoul, Korea). The cells were cultured in Dulbecco's modified Eagle's medium (DMEM) supplemented with 10\% fetal bovine serum (FBS), $2 \mathrm{mM}$ glutamine, $100 \mathrm{unit} / \mathrm{mL}$ penicillin, and $50 \mu \mathrm{g} / \mathrm{mL}$ streptomycin at $37^{\circ} \mathrm{C}$ in a cell incubator in an atmosphere of $5 \% \mathrm{CO}_{2}$. Each concentrated extract was dissolved in DMSO $(50 \mathrm{mg} / \mathrm{mL})$, passed through a sterile $0.2-\mu \mathrm{m}$ syringe filter, and stored at $-20^{\circ} \mathrm{C}$.

Cell viability was determined using the 3-(4,5-Dimethylthiazol-2-yl)-2,5diphenyltetrazolium bromide (MTT) assay [19]. Cells were maintained until 80\% confluence and then pretreated with various concentrations of the sample for $24 \mathrm{hrs}$. The cell medium was replaced with $200 \mu \mathrm{L}$ of MTT solution $(0.5 \mathrm{mg} / \mathrm{mL})$ and incubated for an additional $2 \mathrm{hrs}$ at $37{ }^{\circ} \mathrm{C}$. After washing the cells, insoluble formazan crystals were dissolved in DMSO. Absorbance was measured at $540 \mathrm{~nm}$ by the spectrophotometer using a microplate reader (BioTech, Winooski, VT, USA). Results were expressed as a percentage of the control.

\section{Measurement of production of NO, PGE2 and IL-6}

After 24 hrs of incubation of RAW 264.7 macrophages in DMEM containing 10\% FBS, the medium was replaced with $1 \%$ FBS and phenol red-free medium containing various concentrations of the sample. After 2 hrs of incubation, LPS $(1 \mu \mathrm{g} / \mathrm{mL})$ was added. After an 
additional $22 \mathrm{hrs}$ of incubation, concentrations of NO, PGE2, IL-6, and TNF- $\alpha$ in the culture medium were measured. NO concentration in the conditioned medium was measured by the Griess reaction [20]. An aliquot of culture medium was mixed with Griess reagent and incubated at room temperature. Absorbance was read at $540 \mathrm{~nm}$ using an enzyme-linked immunosorbent assay (ELISA) plate reader $20 \mathrm{~min}$ later. NO concentration was calculated from a standard curve drawn with known concentrations of sodium nitrite. Concentrations of PGE2, IL-6, and TNF- $\alpha$ in the culture medium were determined using ELISA kits (R\&D Systems, Minneapolis, MN, USA) according to manufacturer instructions.

\section{Western blotting}

Cells were lysed in a RIPA buffer (Sigma-Aldrich, Saint Louis, MO, USA) containing protease and phosphatase inhibitors (Roche, Basel, Switzerland) and then incubated on ice for 20 min. Protein concentrations of cell lysates were determined by Bradford protein assay [21]. Equal amounts of protein from each sample were loaded and separated by $8 \%$ SDS polyacrylamide gel electrophoresis and then transferred onto Immobilon ${ }^{\circledR}$ membranes (Millipore, Bedford, MA, USA). The membranes were blocked with 5\% skimmed milk in Tris-buffered saline containing $0.1 \%$ Tween-20 (TBST) for $1 \mathrm{hr}$ and probed with primary antibodies against inducible nitric oxide synthase (iNOS, Santa Cruz Biotechnology, Santa Cruz, CA, USA), cyclooxygenase (COX)-2, or anti- $\beta$-actin (Cell Signaling Technology, Danvers, MA, USA) for $18 \mathrm{hrs}$ at $4^{\circ} \mathrm{C}$. After being washed in TBST, the membranes were incubated with horseradish peroxidase-linked secondary antibodies for $2 \mathrm{hrs}$ at room temperature. Proteins were detected with ECL solution (Pierce, Rockford, IL, USA) and visualized using a luminescent image analyzer (FujiFilm, Tokyo, Japan).

\section{RESULTS}

\section{Yields of ethanol extract and fractions}

Different solvents of increasing polarity were used sequentially to fractionate the ethanol extract (Et) of dried RMF: Hx, DM, EA, Bt, and DW. The yield of extract and fractions from the dried RMF are shown in Table 1.

Table 1. Yield of ethanol extract and fractions from dried RMF

\begin{tabular}{ll}
\hline & Yield (\%) \\
\hline Ethanol extract (Et) & 18.5 \\
Hexane fraction (Hx) & 3.6 \\
Dichloromethane fraction (DM) & 0.5 \\
Ethyl acetate fraction (EA) & 2.8 \\
n-Butanol fraction (Bt) & 3.6 \\
Aqueous fraction (DW) & 5.4 \\
\hline
\end{tabular}




\section{Total phenolic content and total flavonoid content}

Total phenolic and flavonoid contents of RMF extract and fractions are shown in Table 2. EA showed the highest total phenolic and flavonoid contents, followed by the Bt, Et, and DM. DW showed the lowest content of total phenolics and flavonoids.

Table 2. The content of total phenolics and flavonoids of RMF extract and fractions

\begin{tabular}{lll}
\hline & $\begin{array}{l}\text { Total polyphenol } \\
\left(\text { mg TA eq. }{ }^{1)} / \mathrm{g}\right)\end{array}$ & $\left.\begin{array}{l}\text { Total flavonoid } \\
(\mathrm{mg} \mathrm{RT} \mathrm{eq.}\end{array}{ }^{2)} / \mathrm{g}\right)$ \\
\hline Et & $128.7 \pm 4.2^{\mathrm{c} 3)}$ & $65.7 \pm 9.1^{\mathrm{bc}}$ \\
$\mathrm{Hx}$ & $62.5 \pm 4.1^{\mathrm{cd}}$ & $56.9 \pm 22.8^{\mathrm{c}}$ \\
DM & $95.4 \pm 7.0^{\mathrm{c}}$ & $89.2 \pm 12.0^{\mathrm{bc}}$ \\
EA & $565.5 \pm 50.3^{\mathrm{a}}$ & $232.9 \pm 15.6^{\mathrm{a}}$ \\
Bt & $273.1 \pm 15.5^{\mathrm{b}}$ & $102.2 \pm 12.4^{\mathrm{b}}$ \\
DW & $20.6 \pm 3.4^{\mathrm{d}}$ & $1.1 \pm 0.6^{\mathrm{d}}$ \\
\hline
\end{tabular}

Et: ethanol extract of RMF, Hx: hexane fraction, DM: dichloromethane fraction, EA: ethyl acetate fraction, Bt: n-Butanol fraction, DW: water fraction. Data are presented as the mean $\pm \mathrm{SD}$ of three separate experiments. (1) Tannic acid equivalent; (2) Rutin equivalent; (3) Means sharing the same alphabet in superscripts are not significantly different within a column at $p<0.05$ by ANOVA/Scheffé's tests.

\section{Antioxidant activity}

Antioxidant activities of extracts of RMF were determined by three assaying methods: DPPH radical, ABTS radical, and FRAP. DPPH radical-scavenging activity is shown in Table 3 . $\mathrm{IC}_{50}$ of EA and Bt against the DPPH radical was much lower than those in the other fractions, suggesting that EA and Bt have a much stronger antioxidant activity than the others. $\mathrm{ABTS}^{+}$is a blue chromophore produced by the reaction between ABTS and potassium persulfate. ABTS radicalscavenging activity and FRAP of each extract was measured at 100,200 , and $500 \mu \mathrm{g} / \mathrm{mL}$. However, ABTS radical scavenging activity of EA was measured at 50, 100, and $200 \mu \mathrm{g} / \mathrm{mL}$ because it reached around $100 \%$ at $200 \mu \mathrm{g} / \mathrm{mL}$. EA showed the highest ABTS scavenging activity and FRAP, followed by Bt, and Et (Table 4). Overall, EA showed potent antioxidant activity comparable to ascorbic acid and DW showed the lowest antioxidant activity. 
Table 3. DPPH radical scavenging activity of RMF extract and fractions

\begin{tabular}{|c|c|c|c|}
\hline & $\begin{array}{l}\text { Conc. } \\
\text { (ug/mL) }\end{array}$ & $\begin{array}{l}\text { Inhibition rate } \\
(\%)\end{array}$ & $\mathrm{IC}_{50}{ }^{1)}(\mu \mathrm{g} / \mathrm{mL})$ \\
\hline \multirow{4}{*}{$\mathrm{Et}$} & 10 & $23.6 \pm 3.1$ & \multirow{4}{*}{$23.6 \pm 2.0^{\mathrm{c} 2)}$} \\
\hline & 20 & $47.2 \pm 1.0$ & \\
\hline & 30 & $64.4 \pm 6.8$ & \\
\hline & 40 & $79.5 \pm 5.7$ & \\
\hline \multirow{4}{*}{$\mathrm{Hx}$} & 25 & $27.7 \pm 0.3$ & \multirow{4}{*}{$57.2 \pm 1.7^{\mathrm{b}}$} \\
\hline & 50 & $47.9 \pm 2.4$ & \\
\hline & 75 & $65.5 \pm 2.3$ & \\
\hline & 100 & $80.1 \pm 1.7$ & \\
\hline \multirow{4}{*}{$\mathrm{DM}$} & 25 & $25.3 \pm 1.3$ & \multirow{4}{*}{$63.3 \pm 2.2^{b}$} \\
\hline & 50 & $43.5 \pm 1.5$ & \\
\hline & 75 & $59.6 \pm 3.0$ & \\
\hline & 100 & $73.5 \pm 1.4$ & \\
\hline \multirow{4}{*}{ EA } & 50 & $19.5 \pm 1.3$ & \multirow{4}{*}{$5.7 \pm 0.1^{\mathrm{de}}$} \\
\hline & 100 & $36.4 \pm 1.4$ & \\
\hline & 150 & $53.9 \pm 1.7$ & \\
\hline & 200 & $69.9 \pm 2.5$ & \\
\hline \multirow{4}{*}{$\mathrm{Bt}$} & 1 & $7.0 \pm 1.5$ & \multirow{4}{*}{$10.5 \pm 0.2^{\mathrm{d}}$} \\
\hline & 5 & $27.2 \pm 1.9$ & \\
\hline & 10 & $49.9 \pm 0.8$ & \\
\hline & 15 & $68.6 \pm 1.3$ & \\
\hline \multirow{4}{*}{ DW } & 50 & $19.5 \pm 1.3$ & \multirow{4}{*}{$140.4 \pm 5.2^{\mathrm{a}}$} \\
\hline & 100 & $36.3 \pm 1.4$ & \\
\hline & 150 & $53.9 \pm 1.7$ & \\
\hline & 200 & $69.9 \pm 2.5$ & \\
\hline \multirow{4}{*}{$\mathrm{AA}^{3)}$} & 1 & $20.0 \pm 1.0$ & \multirow{4}{*}{$2.3 \pm 0.1^{\mathrm{e}}$} \\
\hline & 2 & $42.3 \pm 0.8$ & \\
\hline & 3 & $65.9 \pm 1.5$ & \\
\hline & 4 & $86.7 \pm 2.9$ & \\
\hline
\end{tabular}

Et: ethanol extract, Hx: hexane fraction, DM: dichloromethane fraction, EA: ethyl acetate fraction, Bt: n-Butanol fraction, DW: water fraction. Data are presented as the mean \pm SD of three separate experiments. (1) Concentration to reduce the initial DPPH radical concentration by $50 \%$; (2) Means sharing the same alphabet in superscripts are not significantly different at $p<0.05$ by ANOVA/Scheffé's tests; (3) Ascorbic acid, positive control. 
Table 4. ABTS radical scavenging activity and FRAP of RMF extract and fractions

\begin{tabular}{|c|c|c|c|c|}
\hline \multicolumn{5}{|c|}{ ABTS radical scavenging activity ( $\mu$ g AA eq. ${ }^{1} / \mathrm{mL}$ ) } \\
\hline & $50 \mu \mathrm{g} / \mathrm{mL}$ & $100 \mu \mathrm{g} / \mathrm{mL}$ & $200 \mu \mathrm{g} / \mathrm{mL}$ & $500 \mu \mathrm{g} / \mathrm{mL}$ \\
\hline Et & \multirow{6}{*}{$56.9 \pm 8.6$} & $40.1 \pm 3.6^{\mathrm{c} 2)}$ & $60.3 \pm 5.8^{b}$ & $102.6 \pm 8.7$ \\
\hline Hx & & $18.0 \pm 3.1^{\mathrm{de}}$ & $32.4 \pm 4.4^{\mathrm{cd}}$ & $64.3 \pm 6.6$ \\
\hline $\mathrm{DM}$ & & $30.3 \pm 4.4^{\mathrm{cd}}$ & $46.0 \pm 5.6^{\mathrm{bc}}$ & $82.8 \pm 6.9$ \\
\hline EA & & $84.8 \pm 8.6^{\mathrm{a}}$ & $106.9 \pm 11.0^{\mathrm{a}}$ & \\
\hline $\mathrm{Bt}$ & & $61.8 \pm 5.3^{b}$ & $88.0 \pm 10.8^{\mathrm{a}}$ & $107.1 \pm 10.6$ \\
\hline DW & & $9.8 \pm 3.2^{\mathrm{e}}$ & $13.6 \pm 3.4^{\mathrm{d}}$ & $32.8 \pm 4.4$ \\
\hline \multicolumn{5}{|c|}{ FRAP $(\mu \mathrm{g}$ AA eq. $/ \mathrm{mL})$} \\
\hline Et & & $12.2 \pm 2.5^{\mathrm{c} 2)}$ & $22.4 \pm 2.0^{\mathrm{c}}$ & $52.2 \pm 4.4^{\mathrm{c}}$ \\
\hline $\mathrm{Hx}$ & & $5.3 \pm 0.8^{\mathrm{d}}$ & $9.8 \pm 0.6^{\mathrm{d}}$ & $22.7 \pm 2.3^{\mathrm{d}}$ \\
\hline $\mathrm{DM}$ & & $6.1 \pm 1.1^{\mathrm{d}}$ & $13.0 \pm 1.8^{\mathrm{cd}}$ & $26.2 \pm 2.4^{\mathrm{d}}$ \\
\hline EA & & $38.4 \pm 2.6^{\mathrm{a}}$ & $76.2 \pm 5.4^{\mathrm{a}}$ & $221.0 \pm 14.2^{\mathrm{a}}$ \\
\hline $\mathrm{Bt}$ & & $26.1 \pm 2.1^{b}$ & $50.4 \pm 6.6^{\mathrm{b}}$ & $125.0 \pm 7.6^{\mathrm{b}}$ \\
\hline DW & & $1.5 \pm 0.4^{\mathrm{d}}$ & $5.5 \pm 0.7^{\mathrm{d}}$ & $12.2 \pm 0.8^{\mathrm{d}}$ \\
\hline
\end{tabular}

Et: ethanol extract, Hx: hexane fraction, DM: dichloromethane fraction, EA: ethyl acetate fraction, Bt: n-Butanol fraction, DW: water fraction. Data are presented as the mean \pm SD of three separate experiments. (1) Ascorbic acid equivalent; (2) Means sharing the same alphabet in superscripts are not significantly different at designated concentration $p<0.05$ by ANOVA/Scheffé's tests.

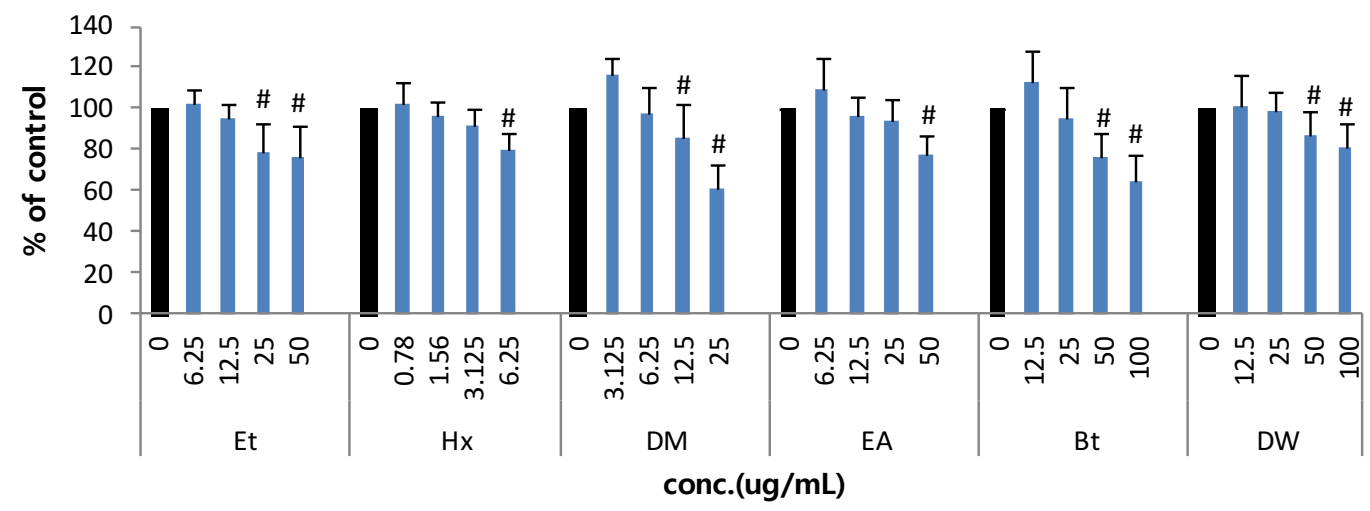

Figure 1. Effect of treatment with RMF extract on cell viability of RAW 264.7 macrophages Et: ethanol extract, Hx: hexane fraction, DM: dichloromethane fraction, EA: ethyl acetate fraction, Bt: n-Butanol fraction, DW: water fraction. Each bar represents the mean \pm SD of five separate experiments. Cells were treated with different concentration of extracts for $24 \mathrm{hrs,}$ and cell viability was determined by MTT assay. \# Less than $90 \%$ of the control. 


\section{Production of IL-6 and TNF- $\alpha$ in RAW 264.7 macrophages}

The LPS treatment resulted in a significantly increased production of IL-6 and TNF- $\alpha$ (Fig 2). Treatment with EA and Bt significantly suppressed IL-6 production $(p<0.05)$ in a dose-dependent manner; whereas, treatment with Et, Hx, and DW did not. Specifically, treatment with DM, EA, and $\mathrm{Bt}$ at their highest concentrations significantly suppressed $(p<0.05)$ IL-6 production of the LPS-treated control to $73.3 \%, 21.8 \%$, and $30.1 \%$, respectively (Figure 2). Treatment with Et, $\mathrm{DM}, \mathrm{EA}$, and $\mathrm{Bt}$ at their highest concentrations significantly suppressed $(p<0.05) \mathrm{TNF}-\alpha$ production of the LPS-treated control to $49.1 \%, 30.6 \%, 58.6 \%$, and $58.6 \%$, respectively (Fig 2). TNF- $\alpha$ concentration in the cells upon treatment with Hx and DW fractions was not measured because $\mathrm{Hx}$ and DW showed relatively low phenolic content and antioxidant activity with no suppression on PGE2 and IL-6 production.
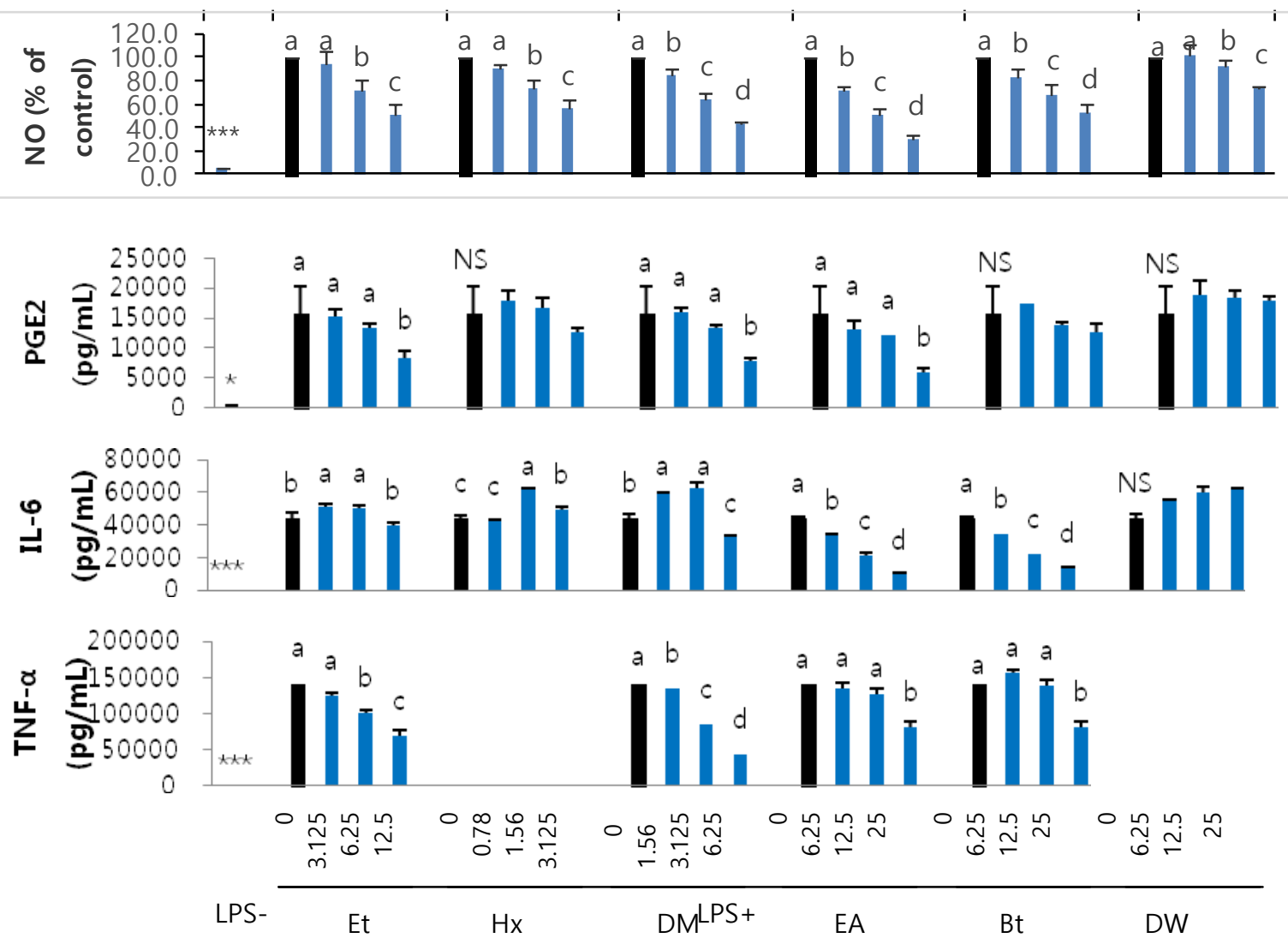

Figure 2. Effects of RMF extract on production of proinflammatory mediators in LPS-treated RAW 264.7 macrophages

Et: ethanol extract, Hx: hexane fraction, DM: dichloromethane fraction, EA: ethyl acetate fraction, Bt: n-Butanol fraction, DW: water fraction. Each bar represents the mean $\pm \mathrm{SD}$ of three separate experiments. Cells were treated with different concentrations of the sample for $2 \mathrm{hrs}$, then LPS $(1 \mu \mathrm{g} / \mathrm{mL})$ was added and incubated for 22 hrs. NO, PGE2, IL-6, and TNF- $\alpha$ concentration in cultured medium was measured. Means sharing the same alphabet in superscript within each sample are not significantly different at $p<0.05$ by ANOVA/Scheffé's tests. Significantly different from LPS-treated control at $* \mathrm{p}<0.05$ or $* * * p<0.001$. NS: not significant. 


\section{Protein expression of iNOS and COX-2 in RAW 264.7 macrophages}

Extremely low levels of iNOS and COX-2 were expressed by cells under basal conditions, but protein expression of iNOS and COX-2 was markedly increased $(p<0.05)$ by LPS treatment (Figure 3). However, pretreatment with the Et, DM, EA, and Bt resulted in significant reduction of iNOS protein expression compared with no treatment $(p<0.05)$. Only Bt pretreatment resulted in significant suppression of both iNOS and COX-2 protein expression in LPS-treated cells. Treatment with Bt showed significant reduction of iNOS and COX-2 $(p<0.05)$ to $48.6 \%$ and $68.8 \%$ of the control at $25 \mu \mathrm{g} / \mathrm{mL}$, respectively. Treatment with the other extracts did not show significant reduction of expression of COX-2 protein (Figure 3).

(A)

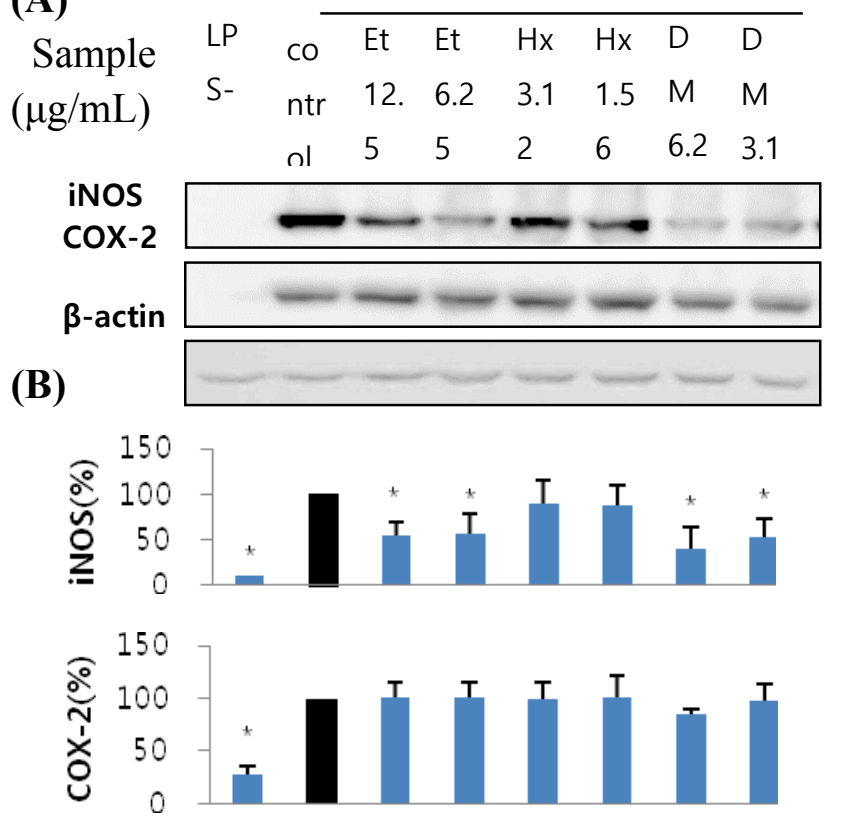

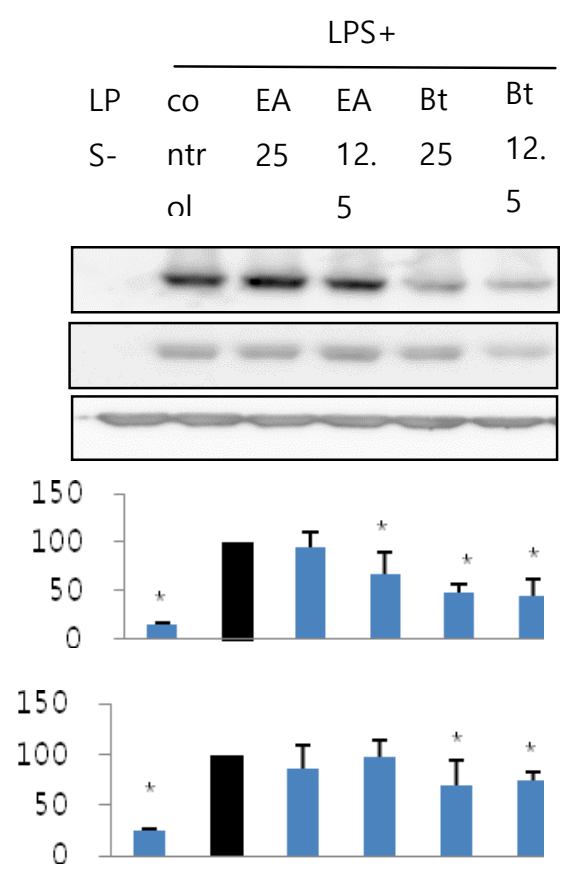

Figure 3 Inhibitory effects of RMF extract on iNOS and COX-2 synthesis in LPS-treated RAW 264.7 macrophages

Et: ethanol extract, Hx: hexane fraction, DM: dichloromethane fraction, EA: ethyl acetate fraction, Bt: n-Butanol fraction. (A) Cells were treated with the sample for $2 \mathrm{hrs,} \mathrm{then} \mathrm{LPS} \mathrm{(1}$ $\mu \mathrm{g} / \mathrm{mL}$ ) was added and incubated for $22 \mathrm{hrs}$. Equal amounts of cellular proteins (50 $\mu \mathrm{g} / \mathrm{well})$ were subjected to Western blotting. (B) The visualized proteins were quantified by densitometry. Each bar represents the mean \pm SD of three separated experiments. *significantly different at $\mathrm{p}<0.05$ from LPS-treated control by ANOVA/t-tests.

\section{DISCUSSION}

ROS are generated constantly and can cause extensive damage to tissues and biomolecules, which can lead to various diseases [22]. Several synthetic drugs protect against oxidative damage, but these drugs have adverse side effects. Thus, the search for efficacious natural antioxidants continues. Phenolic agents present in plants have strong in vitro and in vivo antioxidant activities associated with their ability to scavenge free radicals, break free-radical chain reactions, and chelate metals. Increased consumption of phenolic agents has been correlated with antiinflammatory activity and a reduced risk of cardiovascular disease and certain cancers [23]. 
We discovered that the antioxidant activity of the ethanol extract of RMF and the fractions from the extract were closely correlated with their total phenolic content or total flavonoid content. The total phenolic content in the extracts were significantly correlated with the $\mathrm{IC}_{50}$ for DPPH radical-scavenging activity $(\mathrm{r}=-0.6807, p<0.01)$, ABTS radical-scavenging activity at 100 $\mu \mathrm{g} / \mathrm{mL}(\mathrm{r}=0.9499, p<0.001)$, and FRAP at $500 \mu \mathrm{g} / \mathrm{mL}(\mathrm{r}=0.9814, p<0.001)$. Total flavonoid content was also significantly correlated with the $\mathrm{IC}_{50}$ for DPPH radical scavenging activity $(\mathrm{r}=$ $0.7398, p<0.001)$, ABTS radical scavenging activity at $100 \mu \mathrm{g} / \mathrm{mL}(\mathrm{r}=0.9089, p<0.001)$, and FRAP at $500 \mu \mathrm{g} / \mathrm{mL}(\mathrm{r}=0.8925, p<0.001)$. However, our results cannot be compared with data from other reports because the total phenolic content or antioxidant activity of RMF extracts has not been reported.

Inflammation is a complex process regulated by a cascade of cytokines, growth factors, NO, and PGs by activated macrophages. NO is a short-lived molecule that has an important role in various physiologic processes. However, NO overproduction can activate NF- $\mathrm{KB}$ to induce expression of proinflammatory mediators and can promote inflammation by increasing cyclic guanosine monophosphate, vascular permeability, and transmigration of inflammatory cells to inflammation sites [5,9]. NO toxicity increases considerably if it reacts with a superoxide radical; thereby, forming the highly reactive peroxynitrite anion, which leads to oxidative damage and tissue injury [22]. Chronic generation of the NO radical is associated with various cancers and inflammatory conditions, including diabetes mellitus, multiple sclerosis, arthritis, and ulcerative colitis. PGE2 works as a common final mediator of the induction of fever. Proinflammatory cytokines such as IL- 6 and TNF- $\alpha$ evoke elevated levels of iNOS and COX-2, followed by a significant increase in production of NO and PGE2 [9].

In the present study, EA and Bt fractions from RMF ethanol extract contained denser phenolics and flavonoids than the other fractions and also showed very strong antioxidant activity comparable to ascorbic acid. It was anticipated that EA and Bt would show potent antiinflammatory activity because ROS is a strong inflammatory stimulator. As expected, treatment with EA and Bt resulted in significant suppression of pro-inflammatory mediators such as NO, IL-6, and TNF- $\alpha$ in LPS-stimulated macrophages. The treatment with Et showed the third strongest antioxidant activity and also showed significant suppression of NO, PGE2, and TNF- $\alpha$ production. Treatment with DM resulted in remarkable suppression of NO, PGE2, IL-6, and TNF- $\alpha$ production comparable to EA or Bt; even though, it showed significantly lower total phenolic content and antioxidant activity than EA and Bt. A substance present in DM could have more potent anti-inflammatory activity than antioxidant activity, but further research is needed to discover its identity.

NOS is present in three isoforms: neuronal NOS (nNOS), endothelial NOS (eNOS), and inducible NOS (iNOS). nNOS and eNOS are expressed constitutively and play an important part in normal physiologic activities. In contrast, iNOS-mediated NO production can promote pathologic inflammation. Therefore, selective inhibition of the activity and expression of iNOS is a target for the treatment of inflammation. NO can activate COX, which in turn leads to production of proinflammatory mediators, such as PGs. COX exists in two isoforms: COX-1 and COX-2. Selective inhibition of COX-2 has been suggested to be an approach for the treatment of inflammatory disorders [5]. LPS induces selective expression of COX-2, and dexamethasone selectively inhibits COX-2 expression [24]. 
Allegra et al. [25] found that several polyphenol phytochemicals can inhibit activation of the transcription factors that up-regulate COX-2 expression; thereby, blocking the biosynthetic cascade leading to the synthesis of PG mediators. However, in the present study Et and EA from RMF did not significantly suppress expression of COX-2 protein in LPS-stimulated macrophages even though they had high phenolic content and significantly suppressed PGE2 production. Conversely, treatment with Bt led to significant suppression of expression of COX-2 protein without significant suppression of PGE2 concentration in the culture medium. These results suggest that the extent of PGE2 released from RAW 264.7 macrophages into the culture medium does not always correlate with expression of COX-2 protein. Additionally, EA fraction, which showed the strongest antioxidant activity as well as remarkable suppression of production of NO and PGE2 in macrophages, suppressed the expression of the iNOS protein and COX-2 protein less strongly than Et, DM, and Bt.

These discrepancies in results between NO production and iNOS expression, or between PGE2 production and COX-2 expression, might be because the production of NO and PGE2 was evaluated based on the concentration of accumulated NO and PGE2 released from cells into the medium during the entire incubation time. In contrast, protein expression of iNOS and COX-2 was measured in cell lysates harvested at the end of incubation with LPS and extract. Production of NO and PGE2 can not only be affected by the activities of iNOS and COX-2, but also by substrate availability. Additionally, suppression of PGE2 concentration in the medium caused by treatment with Et, DM, or EA may have been due to suppression of COX-2 activity rather than expression of COX-2 protein, and/or direct suppression of the activity of microsomal PGE2 synthase or inhibition of the activity of 15-hydroxyprostaglandin dehydrogenase, which converts PGs into inactive forms [26].

\section{CONCLUSION}

The ethanol extract of RMF as well as the dichloromethane, ethyl acetate, and n-Butanol fractions had potent antioxidant and/or anti-inflammatory activities in the LPS-stimulated macrophage cellular system. Thus, it is suggested that RMF is a good natural source for the development of a beneficial functional food preventing various chronic diseases, the pathology of which is associated with oxidative stress and inflammation. However, further studies are needed to identify and isolate the compound that elicits strong antioxidant and/or antiinflammatory activity, as well as the underlying mechanism of action.

Competing interests: The authors have no competing interests.

Author's contributions: CSK conceived the study, participated in its design, analyses/interpretation of data, and drafted the manuscript. HIC carried out tests on antioxidant activity and participated in determination of production of NO, PGE2, IL-6, and TNF- $\alpha$ in RAW 264.7 cells. JY carried out western blotting. All authors have read and approved the final version.

Acknowledgements and Funding: The authors thank the Ministry of Science, ICT and Future Planning, Republic of Korea. This research was supported by the fund of this ministry through 
the National Research Foundation (NRF-2014R1A2A2A01-007435). The authors also thank Dahee Son, who helped to extract and fractionate samples.

\section{REFERENCES}

1. Li C, Wang MH. Antioxidant activity of peach blossom extracts. J Korean Soc Apple Biol Chem 2011, 54(1):46-53.

2. Bak MJ, Jeong JH, Kang HS, Jun KS, Ok S, Jeong WS. Cedrela sinensis leaves suppress oxidative stress and expressions of iNOS and COX-2 via MAPK signaling pathways in RAW 264.7 cells. J Food Sci Nutr 2009, 14:269-276.

3. Zhang R, Brennan ML, Shen Z, MacPherson JC, Schmitt D, Molenda CE, Hazen SL. Myeloperoxidase functions as a major enzymatic catalyst for initiation of lipid peroxidation at sites of inflammation. J Biol Chem 2002, 277:46116-46122.

4. Coulibaly AY, Kiendrebeogo M, Kehoe PG, Sombie PAED, Lamien CE, Millogo JF, Nacoulma OG. Antioxidant and antiinfalmmatory effects of Scoparia dulcis L. J Med Food 2011,14(12):1576-1582.

5. Guo DG, Xu L, Cao X, Guo Y, Ye Y, Chan CO, Mok DKW, Yu Z, Chen S. Antiinflammatory activities and mechanisms of action of the peteroleum ether fraction of Rosa multiflora Thunb. hips. J Ethnopharmacol 2011,138:717-722.

6. Scott A, Khan KM, Cook JL, Duronio V. What is "inflammation"? Are we ready to move beyond Celsus? Br J Sports Med 2004, 38:248-249.

7. Koh YJ, Cha DS, Ko JS, Park HJ, Choi HD. Anti-inflammatory effect of Taraxacum officinale leaves on lipopolysaccharide-induced inflammatory responses in RAW 264.7 cells. J Med Food 2010, 13(4):870-878.

8. Blay M, Espinel AE, Delgado MA, Baiges I, Bladé C, Arola L, Salvadó J. Isoflavone effect on gene expression profile and biomarkers of inflammation. J Pharmaceutical Biomedical Anal 2010, 51:382-390.

9. Shan J, Fu J, Zhao Z, Komg X, Huang H, Luo L, Yin Z. Chlorogenic acid inhibits lipopolysaccharide-induced cyclooxygenase-2 expression in RAW 264.7 cells through suppressing NF- $\kappa B$ and JNK/AP-1 activation. Int Immunol 2009, 9:1042-1048.

10. Park GH, lee JY, Kim DH, Cho YJ, An BJ. Ani-oxidant and anti-inflammatory effects of Rosa multiflora root. J Life Sci 2011, 21(8):1120-1126.

11. Cheng BC, Ma X, Kwan H, Tse K, Cao H, Su T, Shu X, Wu Z, Yu Z. An herbal formula consisting of Rosae Multiflorae Fructus and Lonicerae Japonicae Flos inhibits inflammatory mediators in LPS-stimulated RAW 264.7 macrophages. J Enthnopharmacol 2014, 153:922-927.

12. Park KH, Choi SE, Choi YW, Lee DI, Joo SS, Jeong MS, Bang H, Lee CS, Lee MK, Seo SJ, Lee MW. Topical application of two condensed tannins from the root of Rosa multiflora Thunberg for the treatment of atopic dermatitis (AD) in NC/Nga mice. Phytother Res 2011, 25:1564-1569.

13. Wu J, Liu X, Chan C, Mok DKW, Chan S, Yu Z, Chen S. Petroleum ether extractive of the hips of Ros multiflora ameliorated collagen-induced arthritis in rats. J Ethnopharmacol 2014, 157:45-54. 
14. Singleton VL, Orthofer R, Lamuela-Raventos RM. Analysis of total phenols and other oxidation substrates and antioxidants by means of Folin-Ciocalteau reagent. Methods Enzymol 1999, 299:152-178.

15. Chae SK, Kang GS, Ma SJ, Bang KW, Oh MW, Oh SH. Determination of flavonoid content in the citrus fruits. In: Standard Food Analysis. 2nd ed. Seoul: JI-GU publishing; 2002:581-582.

16. Yasushi S, Tsukase N, Keiko S, Hiroe Y, Hisashi Y. Stopped-flow and spectrophotometric study on radical scavenging by tea catechins and model compound. Chem Pharm Bull 1999, 47:1369-1374.

17. Re R, Pellegrini P, Proteggente A, Pannala A, Yang M, Rice-Evance C. Antioxidant activity applying an improved ABTS radical cation decolorization assay. Free Rad Biol Med 1999, 26: 1231-1237.

18. Yildirim A, Mavi A, Kara AA. Determination of antioxidant and antimicrobial activities of Rumex crispus L. extracts. J Agric Food Chem 2001, 49:4093-4089.

19. Mosmann T. Rapid colorimetric assay for cellular growth and survival: application to proliferation and cytotoxicity assays. J Immunol Methods 1983, 65(1-2):55-63.

20. Green LC, Wagner DA, Glogowski J, Skipper PL, Wishnok JS, Tannenbaum SR. Analysis of nitrate, nitrite and [15N] nitrate in biological fluids. Anal Biochem 1982, 126(1):131-138.

21. Bradford MM. A rapid method for the quantification of the microgram quantities of protein utilizing the principle of protein-dye binding. Anal Biochem 1976, 72:240-254.

22. Hazra B, Biswas S, Mandal N. Antioxidant and free radical scavenging activity of Spondias pinnata. BMC Complementary Alternative Medicine 2008, 8:63-72.

23. Xiong L, Yang J, Jiang Y, Lu B, Hu Y, Zhou F, Mao S, Shen C. Phenolic compounds and antioxidant capacities of 10 common edible flowers from China. J Food Sci 2014, 79:C517-C525.

24. Lee SH, Soyoola E, Chanmugam P, Hart S, Sun W, Zhong H, Liou S, Simmons D, Hwang D. Selective expression of mitogen-inducible cyclooxygenase in macrophages stimulated with lipopolysaccharide. J Biol Chem 1992, 267(36):25934-25038.

25. Allegra M, D'Acquisto F, Tesoriere L, Attanzio A, Livrea MA. Pro-oxidant activity of indicaxanthin from Opuntia ficus indica modulates arachidonate metabolism and prostaglandin in LPS-stimlated RAW 264.7 macrophages. Redox Biol 2014, 2:892900.

26. Koeberle A, Northoff H, Werz O. Curcumin blocks prostaglandin E2 biosynthesis through direct inhibition of the microsomal prostaglandin E2 synthase-1. Mol Cancer Ther 2009, 8(8):2348-2355. 